\title{
Diálogo de óleos: propuesta comparativa entre el Autorretrato en verde de Marc Chagall y el Retrato con mujer, niño y perro (Isabella Guerrieri Gonzaga Canossa) de El Veronés
}

\section{Dialogue of oils: comparative proposal between Marc Chagall's Self-Portrait in green and Paolo Veronese's Portrait of Isabella Guerrieri Gonzaga Canossa}

\author{
Magdalena Dardel-Coronado \\ Pontificia Universidad Católica de Valparaíso.Facultad de Filosofía y Educación. \\ Instituto de Historia \\ magdardel@gmail.com
}

Recibido: 27 de febrero de 2012

Aprobado: 16 de abril de 2012

\section{Resumen}

Durante su primera estadía en París (1910-1914), el pintor ruso Marc Chagall conoció, principalmente en el museo del Louvre, a los maestros de la pintura occidental, tal como registró en Mi vida, su autobiografía.

El caso aquí estudiado, la influencia del artista italiano Paolo Caliari en el trabajo del ruso, revela que aunque la historiografía ha pasado por alto las citas a artistas presentes en Mi vida, su lectura a la luz del concepto de tradición de Ernst Gombrich demuestra la importancia que el ruso le otorgó a las obras que conoció en la capital francesa, proponiendo una visión alternativa a la idea de artista rebelde y vanguardista que durante el siglo XX se elaboró en torno a la figura de Chagall.

Palabras clave: Tradición, Louvre, El Veronés, Chagall, Autorretrato

Dardel-Coronado, M (2013) Diálogo de óleos:propuesta comparativa entre el Autorretrato en verde de Marc Chagall y el Retrato con mujer, niño y perro (Isabella Guerrieri Gonzaga Canossa) de El Veronés. Arte, Individuo y Sociedad, 25 (2) 189-202

\begin{abstract}
During his first period in Paris (1910-1914), the russian painter Marc Chagall met, most of all at the Louvre Museum, the masters of western painting, as he wrote in My life, his autobiography.

The case in study, which is the influence of the artist Paolo Caliari in the artwork of the russian painter, reveals the fact that even though historiography has overlooked the quotes of artists present in My life, it's interpretation under the concept of tradition of Ernst Gombrich shows the relevance that the russian gave to the artworks he met at the french capital, proposing an alternative vision to the idea of the rebel and vanguardist artist that was created around Chagall's figure in the twentieth century.

Key Words: Tradition, Louvre, Veronese, Chagall, Self-portrait. .

Dardel-Coronado, M (2013) Dialogue of oils: comparative proposal between Marc Chagall's SelfPortrait in green and Paolo Veronese's Portrait of Isabella Guerrieri Gonzaga Canossa. Arte, Individuo y Sociedad, 25 (2) 189-202
\end{abstract}

Sumario: 1. Introdución, 2. París y el Louvre, 3. Chagall, Cristo y la infancia, 4. Conclusiones, Referencias. 


\section{Introducción}

En "El surrealismo y la pintura" André Breton señaló que con Marc Chagall se inició la pintura moderna (Breton, 1928: 88). Este argumento, adelantado por Guillaume Apollinaire cuando utilizó - casi diez años antes de inventar el término "surrealismo" - la acepción "sobrenatural" para referirse a la obra de Chagall la primera vez que la vio (Chagall, 1931: 168), ha dado pie para considerar al artista ruso como un pintor rebelde que se no adscribió completamente a las vanguardias de las que fue contemporáneo (Venturi, 1956: 17; Sorlier, 1981: 8; Bucci, 1981: 8).

A partir de esta idea, se ha pasado por alto el hecho de que este pintor pudo haber sido influido, durante su primera estadía en París (entre 1910 y 1914), por la historia de la pintura occidental que conoció a través de sus visitas a museos y galerías de la capital francesa, especialmente el Louvre. Ahí se encontró con importantes artistas que aparecen citados en Mi vida, autobiografía escrita en su juventud en donde narra desde su nacimiento hasta su regreso a Rusia una vez comenzada la Primera Guerra Mundial.

Es la lectura de estas citas a la luz de las ideas sobre el concepto de tradición expuestas por el historiador del arte austriaco Ernst Gombrich (1909-2001) las que permiten entender cómo Chagall se acercó a los pintores que conoció en dicha ciudad, específicamente, a El Veronés.

Para el vienés la historia del arte responde, antes que a una sucesión de etapas, a la presencia y pervivencia de las tradiciones. Frente a los cambios técnicos, temáticos y de modas, un pintor es capaz de mantener una tradición en la medida que acuda a artistas anteriores buscando en ellos soluciones que de otro modo no podría obtener (Lorda, 1991: 266-272). Al ser capaz de utilizar, para alcanzar sus propios fines, medios que fueron descubiertos por antiguos maestros pero que luego pasaron a formar parte de la tradición, no solo se inserta dentro de ella, sino que además puede adquirir la maestría artística, en cuanto es capaz de utilizar medios ajenos para llegar a fines propios y acertar con estos. Por ello Gombrich priorizó este concepto sobre el de estilo, pues le permitió centrarse en lo individual, y, a partir de ello, entender cómo cierto artista, en un determinado contexto, acertó y logró una obra maestra.

Esta idea debe ser entendida como la puerta de entrada para demostrar la imposibilidad de todo artista de liberarse de la tradición. Como parte de su formación, observa a los maestros y luego, al momento de pintar, no puede desprenderse de los esquemas mentales que ha construido a partir de la observación. Así, estos esquemas creados por otros artistas son medios o soluciones que tiene a su disposición y que, de acuerdo su idea, llega a utilizar incluso sin tener la intención de hacerlo (Gombrich, 2002: 246-251).

Sin querer reducir o ignorar la complejidad de la teoría del austriaco, la pequeña parte de ella que queda expresada en estas líneas es suficiente para explicar cómo Marc Chagall se insertó dentro de una tradición, al incorporar en su obra esquemas que había observado en otros artistas de los cuales no pudo desprenderse, llegando a acertar en su obra -parafraseando a Gombrich- a partir de los esquemas elaborados por otros pintores. 


\section{París y el Louvre}

Las citas hechas por Chagall a los artistas que conoció estando en Francia nos dan pistas del impacto que en él generaron los maestros occidentales e introducen la posibilidad de que el artista ruso haya tomado elementos de la pintura de estos que luego incorporó en su propia obra. En particular, nos interesa el caso del pintor italiano de la Escuela veneciana Paolo Caliari, El Veronés (1528-1588), citado tres veces en Mi vida. Es la segunda referencia en donde declaró haberlo visto en el Louvre, lo que nos permite establecer un paralelo en la obra de ambos, que para entender es necesario, en primer lugar, conocer el contexto en el que fue hecha.

La llegada de Chagall a París, en abril de 1910, aparece descrita en Mi vida como una situación difícil debido a la nostalgia que el artista sintió por Vítebsk, su ciudad natal. Según la narración, este sentimiento solamente cambió una vez que conoció el Louvre:

Solo la gran distancia que separa Paris de mi ciudad natal me retuvo de regresarme inmediatamente o al menos luego de una semana, o un mes.

Quería incluso inventarme vacaciones, nada más que para poder regresar.

Fue el Louvre el que puso fin a todas estas vacilaciones.

Recorriendo la sala redonda de El Veronés y las salas donde están Manet, Delacroix, Courbet, no deseaba nada más. (1931: 149)

El conflicto interno de Chagall en París solo se resolvió a través de la pintura. La nostalgia que sintió en primera instancia por Vítebsk, se transformó, a través de las visitas al Museo, en una oportunidad para introducirse en la pintura occidental.

Fue de este modo que el artista comenzó a considerar a París como su nueva cotidianeidad. En las primeras páginas de Mi vida, dedicadas a describir su infancia, el artista deja entrever cómo le interesa pintar su cotidianeidad, cuando señala, por ejemplo,

Los arrimos y los tejados, las vigas, las cercas y todo lo que habia detrás [de su casa] me fascinaba.

Y todo lo que había ahi lo pueden ver en mi cuadro "Encima de la ciudad", o bien, se los puedo contar.

Una hilera de estancias, de casitas, de ventanas, de portones, de gallinas, una fábrica cerrada, una iglesia, una pequeña colina (antiguo cementerio, donde ya no se entierra) (1931: 52-53).

Así -y esta idea es reiterativa en la primera parte de la autobiografía- el ruso establece un paralelo entre su vida diaria y su pintura. Según las pistas que nos entrega en Mi vida esta situación se prolongó en París. De esta manera, aquello que conoció en el Louvre determinó su obra en esta misma época, porque encontró en la capital francesa, como él mismo señaló, su "segundo Vítebsk" (1931: 116), idea que está muy presente en su pintura de este primer periodo parisino, uno de sus momentos más fértiles en términos artísticos. En él alternó sus recuerdos de infancia con los descubrimientos hechos en la ciudad, encontrándose, por ejemplo, obras donde mezcla recuerdos de sus orígenes en Vítebsk con elementos propios de París. 


\subsection{Autorretrato con siete dedos}

Un buen ejemplo en donde se puede ver la síntesis de estos dos aspectos son sus autorretratos, uno de sus temas más recurrentes durante esta etapa. En ellos queda de manifiesto la capacidad del artista para acercarse en términos pictóricos a los diferentes movimientos vanguardistas de los cuales era testigo, sin querer formar parte de ninguno de ellos. Ante la inmensa variedad estilística sobre la que trabajó, ninguno de los autorretratos de Chagall puede caracterizarse dentro de alguna vanguardia en específico, aunque se encuentren en ellos diversos elementos que evoquen a los movimientos artísticos contemporáneos. Quizá el mejor ejemplo de esta situación sea Autorretrato con siete dedos de 1911 (Figura 1) en donde se demuestra, en términos formales, la influencia cubista que nunca asumió. En cuanto al uso de los colores, a diferencia de los marrones y grises característicos del movimiento fundado por Picasso, Chagall prefirió utilizar tonos vivos que recuerdan al fauvismo, aunque tampoco se considere deudor de la vanguardia originada alrededor de Matisse. Sobre esta capacidad del artista, Benjamin Harshav señaló:

En sus pinturas podemos encontrar las articulaciones casi geométricas de las formas derivadas del cubismo, la predilección del orfismo por los círculos en el espacio, una exuberancia de influencia fauvista por el color que traspasa los límites de los objetos, la precisión cromática de las formas del suprematismo, el movimiento dinámico y las fuertes diagonales del futurismo, las deformaciones de los rostros y figuras humanas pre-expresionistas, un arreglo de ensueño de los objetos en el espacio representado, anticipando el surrealismo, e incluso múltiples y mínimas decoraciones y ornamentos típicos del movimiento ruso de principios de siglo Mir Iskusstva. (1994: 52).

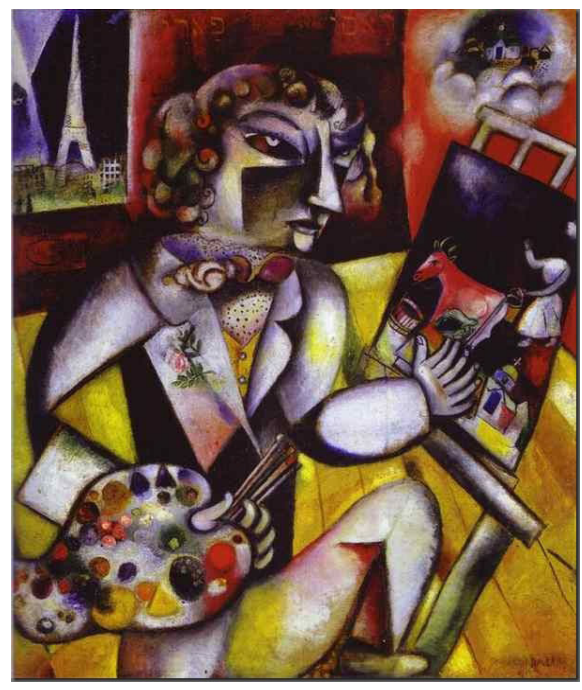

Figura 1. Marc Chagall, Autorretrato con siete dedos, 1911.

(Stedeljik Museum, Amsterdam) 
En este autorretrato el artista representó, a lo lejos, la imagen de la Torre Eiffel donde dejó de manifiesto que, en la pintura, está en París, representada en los mismos términos que en el cuadro París a través de la ventana, de 1913 (Mann, 2006: 677). Sin embargo, también aludió a su infancia en Rusia ya que, por otra parte, Chagall incluyó dos inscripciones en hebreo: arriba, al lado izquierdo (al lado de la Torre Eiffel) París y, al costado derecho, Vítebsk. De este modo, no solamente pensó en su pasado y presente, sino que también propuso que las dos ciudades eran su lugar de nacimiento: Vítebsk, el donde lugar realmente nació y París, en donde -según sus propias palabrasnació como pintor (Harshav, 2004: 673). Además, hay una segunda evocación a sus orígenes en la nube en donde el pintor imagina o recuerda la sinagoga de su ciudad natal. Por otra parte, el título de la pintura es igualmente relevante, ya que Chagall lo tomó de la expresión yiddish "mit ale zibn finger" que significa "hacerlo con siete dedos" y que quiere decir hacer algo con todas las facultades y sentidos, utilizando tanto la razón como las emociones (Mann, 2006: 678). Otro punto central a tener en cuenta en esta pintura es la obra que el artista está realizando dentro de ella. Esta es visiblemente similar a A Rusia, los asnos y los otros (Figura 2), realizada en París hacia esa misma fecha, en donde también incluyó una evocación a su país de origen. Además de volver a aparecer la sinagoga de Vítebsk es fundamental la vaca roja que amamanta a un niño y un cordero. Según señaló el propio Chagall, la representación del niño amamantando alude a sí mismo y a no querer desvincularse de Rusia, aquí representado en la vaca (Schneider, 1946: 123).

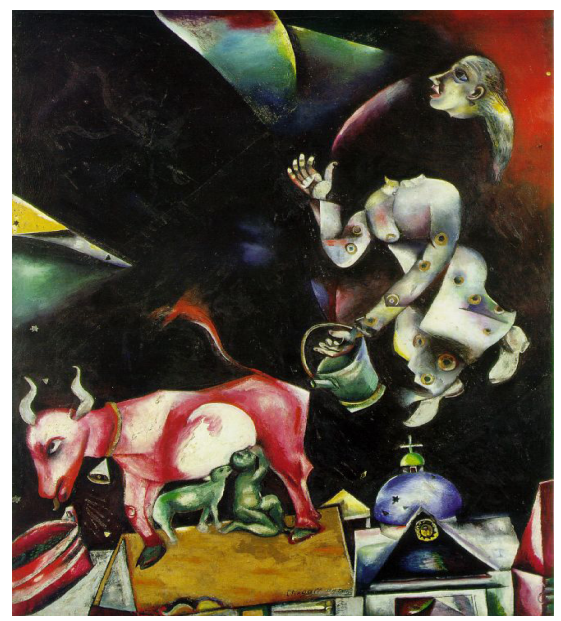

Figura 2. Marc Chagall. A Rusia, los asnos y los otros, 1911.

(Musée National d'Art Moderne, Centre Georges Pompidou, París)

El color del niño y el cordero no es casual: en el periodo parisino de Chagall, el verde fue usado para relacionarse con animales y para aludir a aquello que está recién brotando de la tierra. El verde tiene un sentido de novedad (Schneider, 1946: 122). De ahí que esté presente en otras obras como Yo y la aldea (1911), Amantes en verde (1914) y, años más tarde, en el Violinista en verde (19231924). Este simbolismo es fundamental porque, como veremos más adelante, 
Chagall lo utilizó en pinturas en las que está presente la idea de la infancia. A partir de estos elementos se puede reconocer cómo estas dos obras, Autorretrato con siete dedos y A Rusia, los asnos y los otros constituyen dos buenos ejemplos de cómo Marc Chagall buscó mostrar que, aunque se encontraba en París, recordó y pintó a Rusia, y también cómo fue capaz de transformar el ánimo vanguardista del que fue testigo sin dejar de lado su interés por representar cotidianeidad en Vítebsk.

\subsection{Autorretrato en verde}

Sin embargo, hay otros autorretratos en donde la vinculación con el arte del siglo XX no es tan clara y es necesario salir de ese margen, considerando también la pintura anterior. Tal es el caso de Autorretrato en verde de 1914 (Figura 3) que si bien tiene presente, en palabras de Harshav, la "exuberancia de influencia fauvista que traspasa el límite de los objetos" por su colorido, le debe menos a la vanguardia, y, más aún, es una obra particular porque no manifiesta la relación que tuvo Chagall con el medio artístico que le fue contemporáneo. De este modo, la obra presenta singularidades que la sitúan dentro de un rango especial, sobre todo por ser el único de los autorretratos del artista ruso en donde incluyó, además, otros personajes, en este caso, una mujer y un perro.

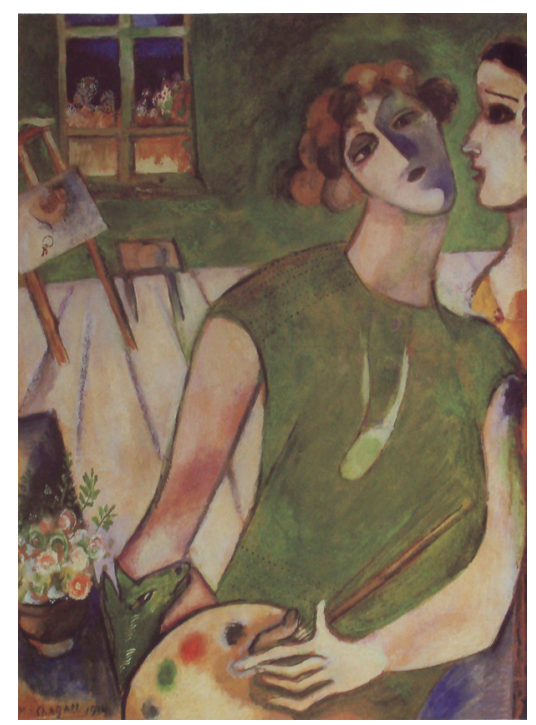

Figura 3. Marc Chagall. Autorretrato en verde, 1914.

(Musée National d'Art Moderne, Centre Georges Pompidou, París).

Esta inclusión guarda una directa relación con una de las obras de El Veronés que el pintor conoció en el Louvre, el Retrato de mujer con niño y perro (15461548)- también llamado Retrato de Isabella Guerrieri Gonzaga Canossa (Figura 4)-, desde donde Chagall habría tomado la composición, transformándola en su propio autorretrato, al reemplazarse por el niño y mantener la mujer y el animal. Para comprender las particularidades de esta pintura, es necesario, en primer lugar, 
referirnos a la presencia de animales tanto en la obra de Chagall como en la de El Veronés. Tras ello, analizaremos el reemplazo del niño por el pintor. A partir de estos dos aspectos, se podrá hacer la vinculación entre la obra de ambos artistas.

En relación a la presencia de animales en la obra del pintor ruso, Lucien Goldmann en su estudio sobre el artista propuso que él entendía el mundo según ciertas categorías mentales y afectivas que se relacionan con el medio en el que fue criado. De esta manera, replicó en su pintura los dos grupos que conoció durante su infancia: judíos y campesinos. El segundo grupo está caracterizado por ser retratado estereotípicamente, lo que incluye la utilización de animales de granja (Goldmann, 1960: 670). De este modo, si bien es común ver en sus telas caballos, cabras, vacas, bueyes y gallos, el Autorretrato en verde es la única obra de este periodo en donde incluyó un perro. Creemos que esta particular presencia nos permite establecer una vinculación con el Veronés, quien retrató perros habitualmente en su obra.

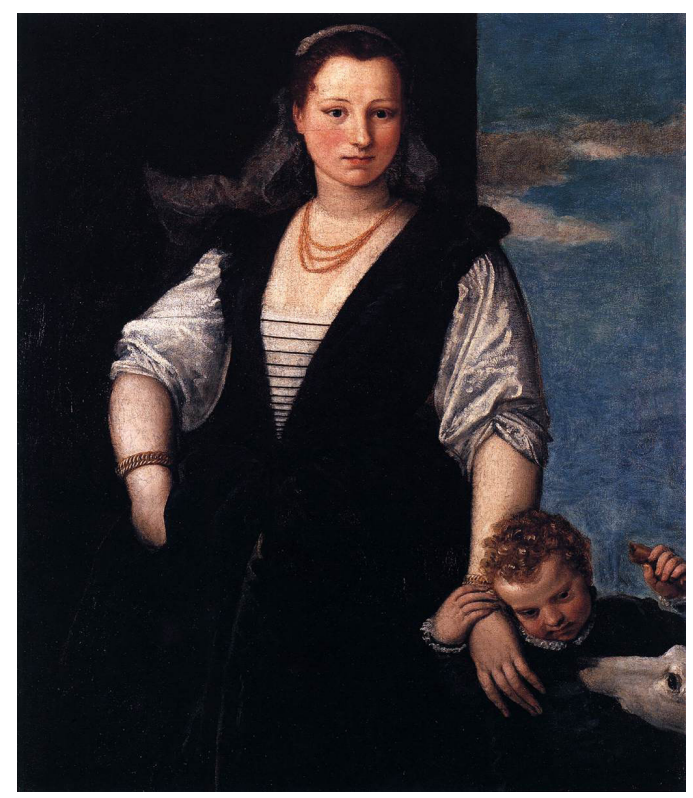

Figura 4. Paolo Caliari, El Veronés. Retrato de mujer con niño y perro, 1546 - 1548.

(Musée du Louvre, París)

El detallado naturalismo con el que el italiano retrató los canes llamó la atención de Vasari e hizo que Jan Bialostocki los definiera como retratos de perros, de los que según él Caliari es el mayor exponente. Su variada manera de representarlos le permitió situarlos en distintos tipos de obra, como por ejemplo en lujosas fiestas ( $\mathrm{La}$ cena en la casa de Levi), motivos religiosos (Anunciación), escenas de caza (Niño con galgo), motivos mitológicos (Cupido con dos perros) y en múltiples retratos. Estos se encuentran tan comúnmente presentes que incluso fue un argumento para que en 1573 el artista italiano compareciera ante el Santo Oficio por la extrema libertad con la que retrataba escenas religiosas, lo que incluía a los perros, cuya representación, al ser irracionales y privados de vida eterna, era considerada incompatible con el decoro 
de un hombre religioso. De hecho, el Concilio de Trento prohibió la representación de animales domésticos en pinturas bíblicas a menos que fueran imprescindibles para la historia narrada. Esto hizo que artistas como Nicolas Poussin no los incluyera nunca en sus obras, incluso cuando era relevante para el motivo pintado. De manera inversa, en El Veronés se encuentran presentes aun cuando no cumplían ningún rol en la escena pintada (Bialostocki, 1990: 222).

Tanto la minuciosa representación como la cercanía que los perros tienen con los personajes llevan a concluir a Biaolostocki que no es extraña la numerosa presencia de canes en las composiciones del italiano y que esta se debe al amor que sentía por estos animales. De este modo, concluyó que no se puede atribuir a los perros de El Veronés una función simbólica en específico:

Su presencia puede ser explicada solo por una predilección particular del pintor, mientras que el modo en que fueron pintados indican con qué amor el maestro véneto observaba sus formas y comportamiento. (1990: 228)

En este punto coincide Antoine Orliac, biógrafo de Caliari, cuando se detuvo al describir las características de los perros pintados por este artista, realzando su nobleza:

Tiziano, que tenía un amor apasionado por las formas femeninas y estaba interesado en la psicología de los rostros masculinos, al parecer se preocupó poco por los animales. Cuando tuvo que introducir un perro, una oveja, un conejo o una paloma en sus composiciones, usó el subterfugio del estilo. El Veronés es más instintivo en su actitud. Él expresa la distinción de un perro de raza, que vive alrededor de mesas nobles y que contrasta con los leales mestizos nacidos de un oportuno cruce, que juegan con niños en modestos interiores (1940: 28).

A partir de esta obra y otras que conoció del pintor italiano, el ruso encontró en El Veronés un maestro en representación de canes, y acudió a él en términos compositivos cuando pintó el único perro de su periodo parisino.

Así, en el Autorretrato en verde el artista dispuso al perro en el extremo izquierdo de la obra, mientras que El Veronés lo situó al costado derecho. Tal como el del italiano, el perro de Chagall solo asoma la cabeza hacia arriba teniendo una actitud observadora frente a los personajes pero, a diferencia de la obra de Caliari, en donde el niño juega con el perro, la pareja pintada por el ruso ignora al animal. Además, pareciera que Chagall tuvo en cuenta que los perros predilectos por El Veronés para los retratos eran los galgos, y pese a que no lo representa con el naturalismo propio del maestro italiano, su perro sí guarda algún parecido con esa raza.

\section{Chagall, Cristo y la infancia}

Por otra parte, el segundo elemento que se destaca para analizar la vinculación entre ambos artistas es el reemplazo del niño por el pintor, lo que responde al concepto que el propio Chagall tenía de sí mismo, ya que siempre se consideró como un niño: 
En el Louvre era donde me sentía más a gusto.

Amigos desaparecidos hace mucho tiempo. Sus plegarias, las mías. Sus telas iluminaban mi rostro infantil (1931: 159).

La vinculación de Chagall con la infancia se reafirma a través de la utilización del color verde como parte fundamental de la pintura, que Chagall utiliza para sí, pero no para la mujer, Bella Rosenfeld, su prometida, constantemente retratada en sus obras. Como ya se mencionó, acudió al color verde para retratar lo nuevo y para vincularse con los animales, que en este autorretrato también tiene ese color, como reafirmación de su autopercepción infantil y manera de ratificar el vínculo entre el niño y el perro.

Es probable que la relación que Paolo Caliari hace entre los perros y la infancia tenga una resonancia mayor. En su pintura los canes se encuentran comúnmente cercanos a los niños, como por ejemplo La santa cena de Emaús (1559), La santa cena en casa de Simón (1560), la versión de Las bodas de Caná de 1560, Marte y Venus (h. 1570) y Niño con galgo (h. 1570).

Cesare Ripa en su Iconología de 1593 vinculó el perro a los conceptos de fidelidad, investigación, persuasión, consejo, espía y juventud, es decir, ligado al futuro. En específico, para el caso de la juventud, una de sus representaciones es la de un joven alto acompañado de un perro de caza, tal como el de Niño con galgo del artista véneto. Si bien la obra de Ripa fue editada cinco años después de la muerte de Caliari, bien pudo el pintor tener conocimiento de algunas de estas representaciones y utilizarlas en su pintura, considerando la relación entre los canes, la infancia y el futuro. Sin embargo, en algunas de sus obras más importantes, como por ejemplo Las bodas de Caná (versión de 1563) y La cena en casa de Levi (1573) no vinculó a los niños y a los perros, aunque ambos aparecen.

Si volvemos a Chagall, veremos que la relación entre el artista y la infancia es un tema que trató frecuentemente en sus pinturas, siendo un buen ejemplo de ello Gólgota (también llamada Dedicada a Cristo), pintura de 1912 (Figura 5) en donde presentó a Jesús crucificado como niño y que, además, tiene al color verde como el predominante. Según el planteamiento que hizo Ziva Amishai-Maisels, Chagall estableció un paralelo entre él y Jesús, aludiendo al antisemismo que sufrió en su infancia. Como argumento para su propuesta, la autora analizó el estudio previo para esta pintura (figura 6), donde bajo la inscripción INRI, que aparece en ruso, está escrito en hebreo Chagall, proponiendo una analogía entre él y Cristo (AmishaiMaisels, 1991: 148).

El paralelo que el artista propuso entre él y el Crucificado volvió a aparecer en El descendimiento de la cruz de 1941 (figura 7) en la que representó a Cristo adulto, donde remplazó nuevamente la inscripción INRI por su nombre, esta vez en alfabeto latino. Independiente del repetitivo paralelo entre él y Jesús, nos interesa tener en cuenta cómo se sintió identificado con Cristo y cómo esa vinculación en 1912, momento en que estaba en París, correspondía a la de Cristo niño. En ese mismo periodo, dos poetas amigos del pintor, el italiano Ricciotto Canudo y el suizo Blaise Cendrars, señalaron este parecido(Harshav,2004:190 y 208). 


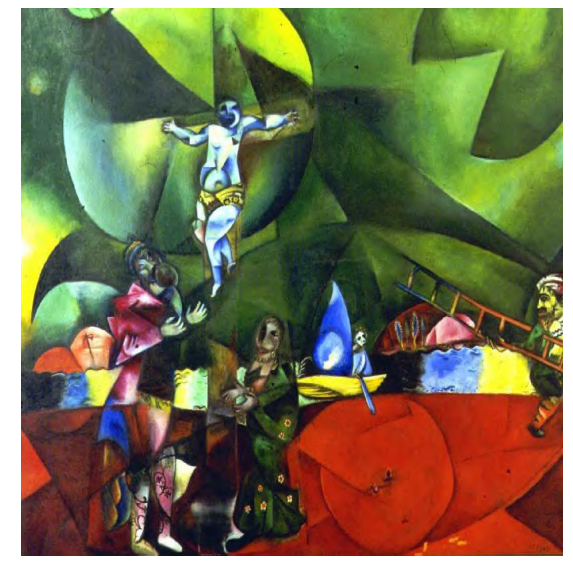

Figura 5. Marc Chagall. Gólgota, 1912. (Modern Museum of Art, Nueva York)

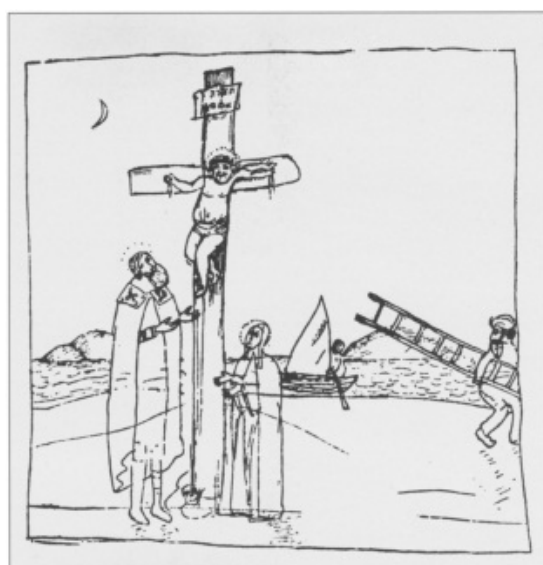

Figura 6. Marc Chagall. Estudio para Gólgota, 1908 - 1912. (Modern Museum of Art, Nueva York) 


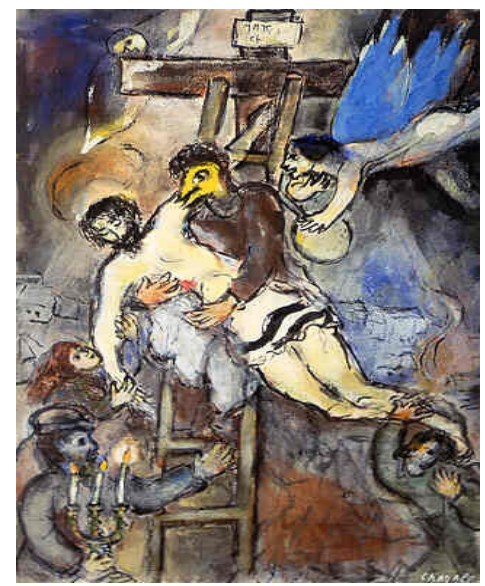

Figura 7. Marc Chagall: El descendimiento de la cruz, 1941. (Colección particular)

Incluso antes de llegar a Francia, entre 1908 y 1910, realizó tres pinturas que tituló Sagrada familia (Figura 8) en donde la retrató como una típica familia judía campesina. La peculiaridad radica en que representó al niño con barba. En esta obra, Chagall pensaba en la historia que cuentan los campesinos rusos a sus hijos sobre Dios, niño y hombre a la vez, que los judíos crucificaron (Goldman, 1960: 673).

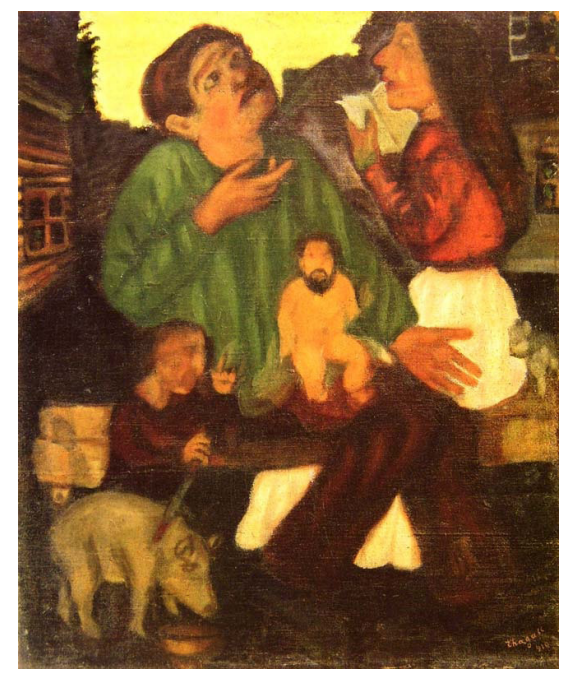

Figura 8. Marc Chagall. Sagrada familia, 1910. (Kunsthaus, Zurich)

Respecto a esta serie, el mismo Chagall señaló: 
Ya en 1908 había pintado una Sagrada familia con un pequeño Jesús barbado. Para mí, Cristo es un poeta y un profeta de primer orden. Me até a él como símbolo de alta tensión (Clay, 1969: 49).

Las constantes referencias, tanto en Mi vida como en las pinturas de este periodo, a su familia, a Vítebsk y a la infancia no pueden explicarse solamente como resultado de la nostalgia que el ruso sintió al llegar a París. Las evocaciones a la niñez responden también al interés del artista por esta etapa de su vida, con la que siempre se sintió cercano. En una entrevista efectuada en 1962 señaló que su permanente conexión con la infancia fue a partir del constante miedo que sentía, y aunque en un principio su debilidad física ante los demás lo asustaba, este temor fue reemplazado por la angustia de dejar de ser niño:

Fue solamente más tarde, con la edad, que comprendí cuánto miedo tenía durante mi juventud. Miedo de crecer. Sabía que no sería siempre pequeño, joven, lindo. No sabía lo que iba a hacer. Era menos firme que los otros niños (Clay, 1969: 49-50).

Otra cita de Mi vida que se relaciona con esta es igualmente relevante y se vincula claramente con lo que señalábamos anteriormente, sobre todo con el niño de la imagen de la Sagrada familia y la vinculación Chagall-Cristo como niños:

Cada año que pasaba, me sentía avanzando hacia umbrales desconocidos. Sobre todo el día que mi padre, vestido con el taled [tejido usado por los judios en sus ceremonias religiosas], murmuró sobre mi cuerpo infantil de trece años la oración expiatoria. ¿Qué podía hacer?

¿Seguir siendo un niño inocente?

¿Rezar por la mañana y por la noche y donde quiera que vaya, cualquier cosa que me lleve a la boca y cualquier palabra que oiga, pronunciar en seguida una oración?

$¿ O$ huir de la sinagoga y, rechazando los libros, la ropa sagrada, correr por las calles hacia el rio?

Tenía miedo de mi futura mayoría de edad, miedo de llegar también a tener todos los síntomas del hombre adulto, incluso la barba.

En aquellos días tristes, solitarios, estos pensamientos me hacian llorar al atardecer, como si me pegaran o como si me anunciaran la muerte de mis padres.

Observaba a través de la puerta entreabierta el gran comedor oscuro. No había nadie. El espejo colgando en libertad, solo y frío, miraba de manera extraña.

No solía mirarme en él. Tenía miedo que alguien me sorprendiera mientras me admiraba.

Nariz larga de anchos agujeros, iqué le vamos a hacer! Pómulos salientes, perfil rudo.

A veces, durante esta contemplación, me quedaba pensativo.

¿Qué sentido tiene mi juventud?

En vano me estoy haciendo mayor. Belleza inútil y pasajera que se congela en el espejo.

Recién cumplidos los trece años, mi infancia despreocupada terminará y todos los pecados caerán sobre mi cabeza. ¿Pecaré? (1931: 99-100). 
La larga descripción que el artista hace del momento de su Bar Mitzvah merece ser citada porque en ella encontramos todos los tópicos que ya se habían presentado en las otras referencias. Chagall temía a la adultez, a los cambios de sus facciones infantiles. De cierta manera en el Louvre ese proceso se ve detenido, ahí se volvió a sentir niño porque encontró grandes pintores, maestros frente a los cuales él consideraba estar muy lejos y que lo devolvieron metafóricamente a su infancia.

\section{Conclusiones}

El paralelo con el niño del retrato de El Veronés adquiere mucho sentido considerando estas referencias y que, además, la pintura que conoció en el Louvre "iluminó su rostro infantil". Al incluirse a sí mismo pero reemplazándose por el hijo de la mujer retratada en la obra del italiano, no solamente evocó esta pintura, sino que también reveló la percepción que tenía de sí mismo frente a los pintores que observó en el Museo, a quienes calificó como dioses (1931: 154). Además, dejó de manifiesto nuevamente interés por pintar su cotidianeidad, al reemplazar Vítebsk por París y la casa paterna por el Louvre, el lugar en donde se sentía más a gusto. A través de esta relación se puede señalar que el Museo motivó a Chagall a llamar a la capital francesa como su "segunda Vítebsk", porque fue ahí donde cambió desde una pintura basada en recuerdos infantiles a otra influida por maestros europeos. En el caso particular de esta pintura, introdujo en ella un perro, porque este animal, inusual para su obra de Vítebsk, responde a su nueva vida diaria, la de París y las visitas al Louvre.

Sin pretender copiar la realidad, Chagall tomó de ella ciertos elementos que utilizó de manera constante, aludiendo a su cotidianeidad y lo que vio en ella. Para sus primeros años de pintor, son la ciudad, su familia, sus costumbres. Años más tarde, señaló sobre Vítebsk: "En la ciudad puedes estar, pero fuera de la ciudad no es para ti. Incluso no es posible hacer un jardín. Han visto, en mis pinturas, no hay lugar para un jardín..." (Clay, 1969: 47).

Con esta cita el artista explicó cómo le interesaba tomar aspectos de su vida diaria al momento de pintar. Si en Vítebsk no hay jardines, en sus pinturas tampoco los hay, ya que no son parte de lo que observa diariamente. Al llegar a París, su cotidianeidad cambia, y, con ello, lo que pinta. El nuevo escenario de Chagall tiene como centro el lugar que le daba más comodidad, el Louvre. Al transformarse el Museo en su nueva cotidianeidad, su pintura comienza a aludir a ella.

El cambio entre París y Vítebsk se hizo evidente en cuanto Chagall se dio cuenta que su nueva casa paterna era este Museo. De este modo, se inició un conflicto, porque si bien pretendía seguir pintando de acuerdo a un vocabulario propio generado desde su vida diaria, la cotidianeidad a la que se enfrenta en París trajo consigo un nuevo vocabulario pictórico, el de los antiguos maestros que aquí conoció.

Este conflicto revela la forma en la que Chagall se acercó a la tradición estando en la capital francesa. Sin dejar de lado los intereses que estaban desde sus comienzos como pintor, se acercó a la pintura occidental a través del Louvre. De este modo se hizo parte, sin darse cuenta, de una tradición. Esta es la que aparece en Mi vida en donde las continuas referencias a los artistas que conoció durante su estadía en París demuestran como este pintor, considerado de entre los más rebeldes del siglo XX al 
no haberse incorporado a ningún movimiento establecido, sí estuvo inserto dentro de una tradición, y el diálogo que estableció con El Veronés a través de su Autorretrato en verde es una clara prueba de ello.

\section{Referencias}

Amishai-Maisels, Z. (1991). Chagall's White Crucifixion. Art Institute of ChicagoMuseum Studies Vol. 17 (N²), pp. 138-153.

Bialostocki, J. (1990). Il cani di Veronese. Gemin, Massimo: Nuovi studi su Paolo Veronese. Venecia, Arsenale editrice, pp. 222-230.

Breton, A. (2002). Le surrealisme et la peinture. París: Gallimard.

Bucci, M. (1971). Marc Chagall. Barcelona: Nauta.

Chagall, M. (1931). Ma vie. París: Librarie Stock.

Clay, J. (1969). Visages de l'art moderne: entretiens avec: Arp, Chagall, Albers, Gabo, Moore, Giacometti, Hatung, Vassarely, Menessier, Soto. Laussanne: Raconte. Harshav, B. (1994). The role of language in Modern Art: on texts and subtexts in Chagall's paintings. Modernism/Modernity. Vol. 1, ( $\left.{ }^{\circ} 2\right)$, pp.51-87.Harshav, B. (2004). Marc Chagall and his times. A documentary narrative. Stanford: Stanford University Press.

Goldmann L. (1960). Sur la peinture de Chagall, réflexions d'un sociologue. Annales. Économies, Sociétés, Civilisations. Año 15 ( $\left.\mathrm{N}^{\circ} 4\right)$, pp. 667-683.

Gombrich, E. (2002). Arte e ilusión. Estudios sobre la psicología de la representa ción pictórica. Londres-Nueva York: Phaidon.

Mann, B. (2006). Visions of Jewish Modernism. Modernism/Modernity, Vol. 13 ( ${ }^{\circ}$ 4), pp. 673-699.

Lorda, J. (1991). Gombrich: una teoría del arte. Barcelona: Ediciones Internacionales Universitarias.

Orliac, A. (1940). Veronese. Londres: William Heinemann.

Ripa, C. (1996). Iconología. Madrid: Akal.

Schneider, D. (1946). A psychoanalitic approach to the painting of Marc Chagall. College Art Journal, Vol. 6 ( $\mathrm{N}^{\circ}$ 2), pp. 115-124.

Sorlier, C. (1981). Chagall. Blume: Barcelona.

Venturi, L. (1956). Chagall, étude biographique et critique. París: Editions d'Art Albert Skiro.

Vasari, G. Le Vite. Edizioni Giuntina e Torrentiniana. Volumen V. Recuperado de http://biblio.signum.sns.it/vasari/consultazione/Vasari/indice.html\#contents 